\title{
Congenital Anomalies in the Heart with Hypertrophic Cardiomyopathy
}

\author{
JANE SOMERVILLE AND LAWSON MCDONALD
}

From the Institute of Cardiology, National Heart Hospital, London W.1

The aetiology of hypertrophic cardiomyopathy remains unknown. Various theories have been suggested, and there is evidence that in some patients the condition may be inherited (Davies, 1952). The association of additional congenital defects in the heart in three patients may throw light on the cause of this obscure disease, and is reported below.

\section{CASe Reports}

Case 1. A man, born in October 1932, first attended the National Heart Hospital at 16 years. There was no family history of heart disease, but no relatives were examined. A murmur was noted at 7 months and he was symptom free throughout childhood and adolescence. He played rugby football until the age of 28 , but since 32 he has had slight dyspnoea on effort, which has not increased.

The physical signs at the age of 26 suggested pulmonary valvar stenosis. There was a large " $a$ " wave in the jugular venous pulse, an impalpable cardiac impulse owing to obesity, and in the pulmonary area an ejection click, loud and long ejection systolic murmur, and delayed and diminished pulmonary component of the second heart sound. At 35 an atrial sound was heard, the second sound was single, the ejection murmur was short, and the arterial pulse was jerky.

The electrocardiogram when he was 16 showed right ventricular hypertrophy, but by the age of 28 severe $T$ wave inversion had developed over the right ventricle, and at 30 the electrical axis had changed from normal to left (Fig. 1).

Chest radiographs showed that dilatation of the main pulmonary artery was a constant feature from the age of 16 years, and that cardiomegaly had been present since the age of 22 .

The results of repeated cardiac catheterization are summarized in Table $I$.

Right ventricular angiocardiography at 21 confirmed the presence of pulmonary valvar stenosis which appeared to be mild (Fig. 2). Right and left ventricular angiocardiography at 33 demonstrated gross changes of hypertrophic cardiomyopathy, involving both ventricles

Received March 14, 1968.
(Fig. 3). There was no evidence of aortic valvar stenosis.

Diagnosis. Pulmonary valvar stenosis associated with biventricular hypertrophic cardiomyopathy.

Case 2. A boy, born in April 1960, weighed $4989 \mathrm{~g}$. (11 lb.) at birth and was 3 weeks overdue. He was always slow to gain weight and his mother thought he looked "odd" as a baby in comparison with her other children. Apart from tiring easily he had no symptoms. A heart murmur was heard at a school medical examination at 5 years. There was no consanguinity in the family nor evidence of heart disease. The parents and 4 sibs were examined and none had any abnormality on physical, radiographic, or electrocardiographic examinations. The patient looked different from his sibs who resembled one another.

The physical signs at age 7 years (1967) included small stature (below normal percentiles for height) and a strange face and build, with some of the features seen in mosaic forms of Turner's syndrome (Fig. 4). Chromosome studies on the blood, however, showed no abnormality, and the karyotype was normal. No tissue cultures were performed. The jugular venous pulse showed a $3 \mathrm{~cm}$. " $a$ " wave above the " $v$ " wave. The arterial pulses were normal. The cardiac impulse indicated biventricular hypertrophy. On auscultation in the pulmonary area there was a moderate ejection systolic murmur, and wide splitting of the second heart sound which only moved $0.05-0.06 \mathrm{sec}$. (Fig. 5). At the apex there was an atrial systolic murmur and a late systolic murmur which became pansystolic after effort. A variable delayed diastolic murmur which increased with inspiration was heard along the left sternal edge.

The electrocardiogram (Fig. 6) showed left axis deviation and a QS pattern in leads II, III, VF, V5, and V6, with an rsR complex in V1.

Chest radiograph showed a cardiothoracic ratio of 52 per cent, plethoric lungs, and prominence of both atria (Fig. 7).

The findings at cardiac catheterization in 1967 are given in Table II.

Left ventricular angiocardiography in 1967 showed 


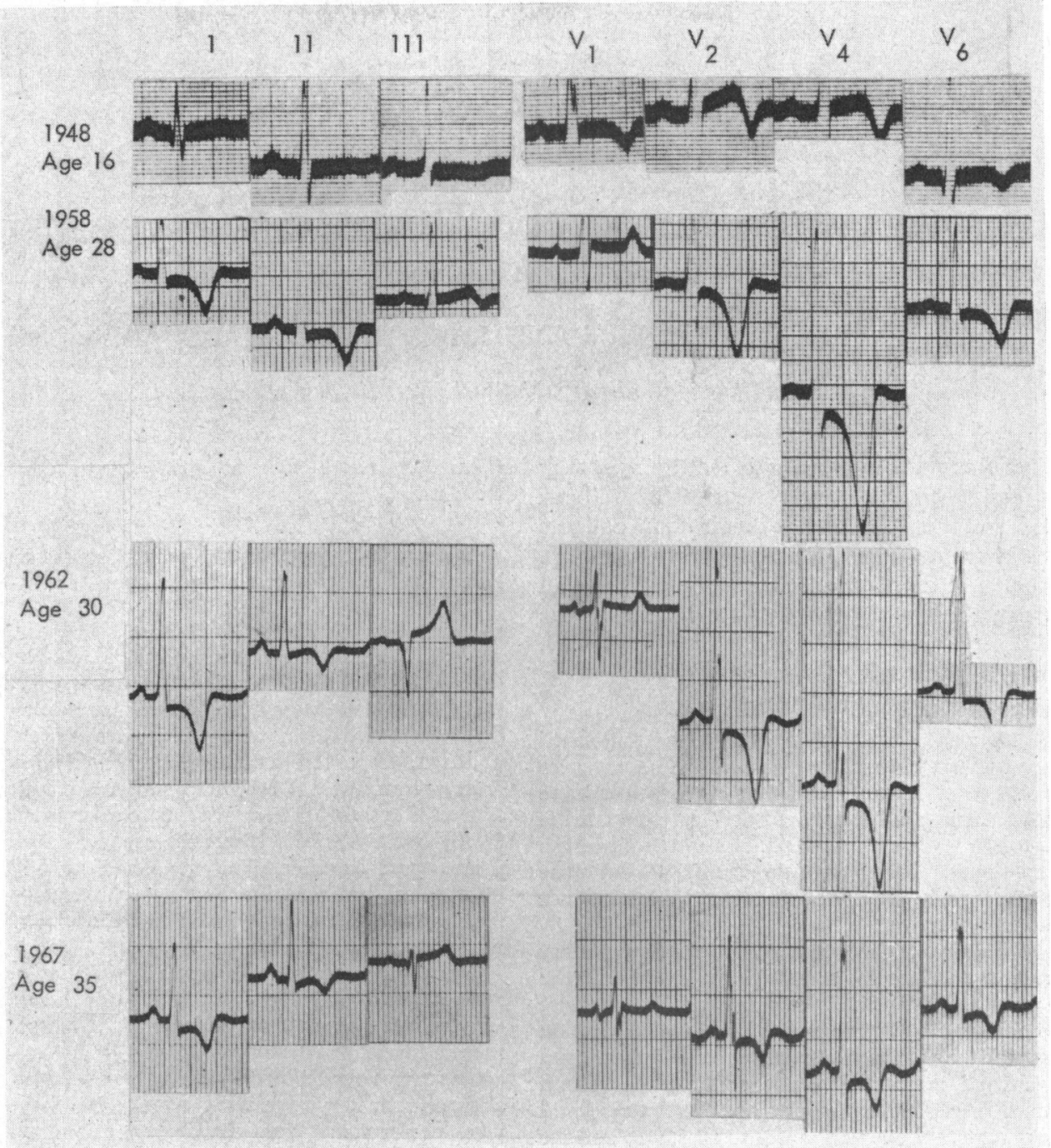

FIG. 1.-Serial electrocardiograms from Case 1 showing an unusual change in electrical axis after the age of 28 , and right ventricular hypertrophy changing to left ventricular hypertrophy.

TABLE I

SUMMARY OF HAEMODYNAMIC DATA FROM CASE 1

\begin{tabular}{|c|c|c|c|c|c|c|c|}
\hline \multirow{2}{*}{$\begin{array}{c}\text { Year of } \\
\text { catheterization }\end{array}$} & \multicolumn{7}{|c|}{ Pressures (mm.Hg) } \\
\hline & $\begin{array}{l}\text { Pulmonary } \\
\text { artery }\end{array}$ & $\begin{array}{l}\text { Right } \\
\text { ventricular } \\
\text { outflow }\end{array}$ & $\begin{array}{l}\text { Right } \\
\text { ventricular } \\
\text { body }\end{array}$ & $\begin{array}{c}\text { Right } \\
\text { atrial } \\
\text { "a" waves }\end{array}$ & $\begin{array}{l}\text { Pulmonary } \\
\text { capillary } \\
\text { venous }\end{array}$ & $\begin{array}{l}\text { Systemic } \\
\text { artery }\end{array}$ & $\begin{array}{c}\text { Left } \\
\text { ventricle }\end{array}$ \\
\hline $\begin{array}{l}1953 \\
1959 \\
1965\end{array}$ & $\begin{array}{l}16 / 4 \\
15 / 5 \\
14 / 5\end{array}$ & $\begin{array}{l}35 / 0 \\
25 / 0 \\
30 / 0\end{array}$ & $\begin{array}{l}130 / 0 \\
35 \cdot 5 / 0 \\
150 / 0\end{array}$ & $\begin{array}{l}5 \\
5 \\
8\end{array}$ & $\underline{7 / 5}$ & $\begin{array}{l}160 / 110 \\
105 / 75 \\
130 / 75\end{array}$ & $\begin{array}{l}\overline{-} \\
130 / 0 \\
a=17\end{array}$ \\
\hline
\end{tabular}




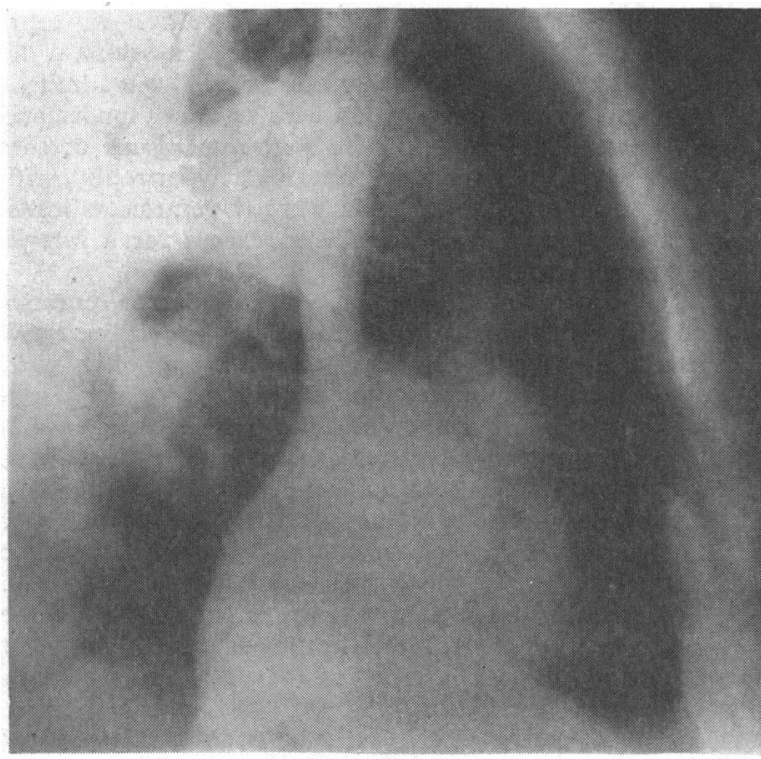

(a)

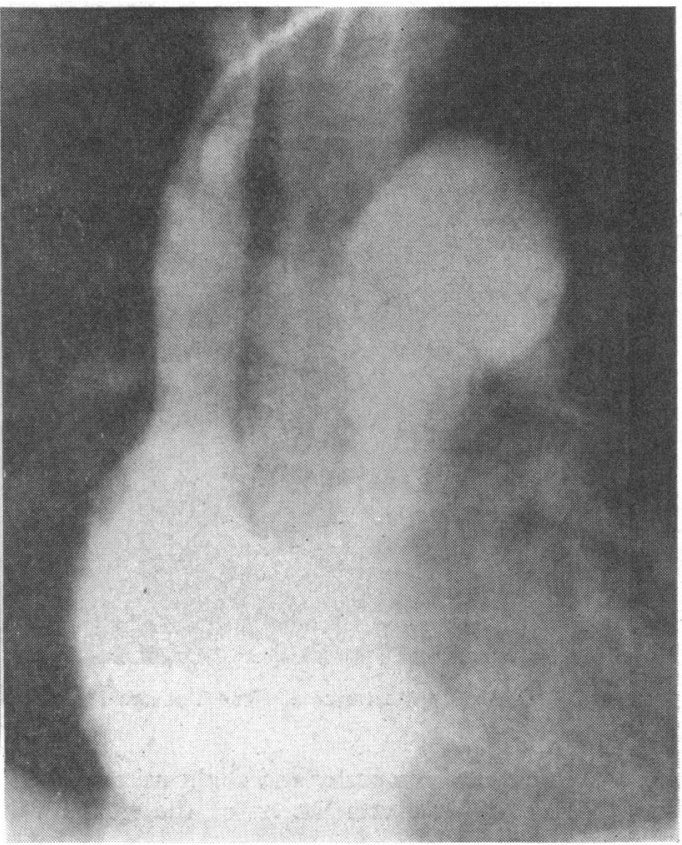

(b)

Frg. 2.-Angiocardiogram from Case 1 in 1953, from injection of contrast medium into the superior vena cava, demonstrating mild pulmonary valvar stenosis and gross post-stenotic dilatation of the pulmonary artery.

(a) Right lateral view; (b) antero-posterior view.

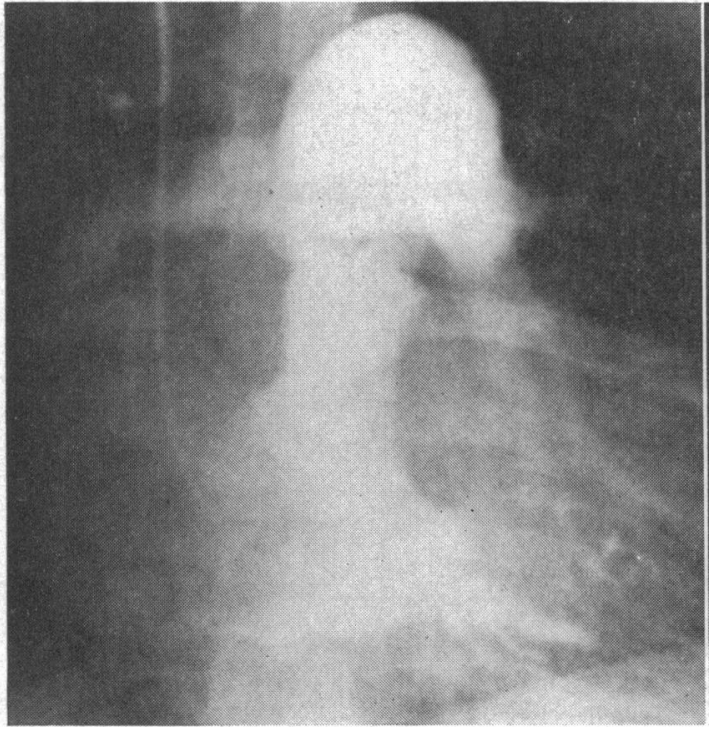

(a)

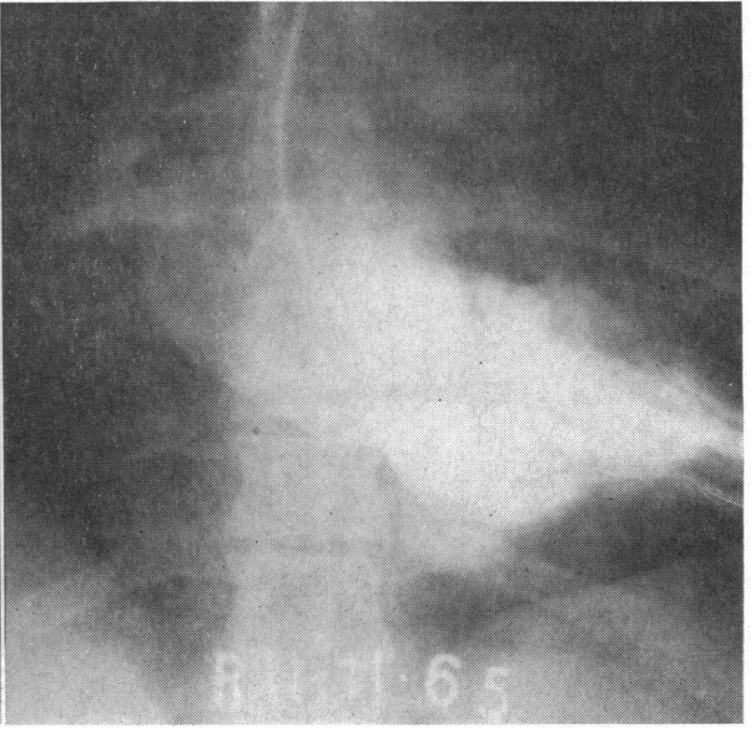

(b)

FIG. 3.-Selective angiocardiograms from Case 1 performed in 1967. (a) Right ventricular angiocardiogram showing septal bulging into the cavity and massive hypertrophy of the right ventricular muscle reducing the cavity to a slit near its apex. (b) Left ventricular angiocardiogram showing left atrial opacification from mitral regurgitation, and massive hypertrophy of the muscle. 


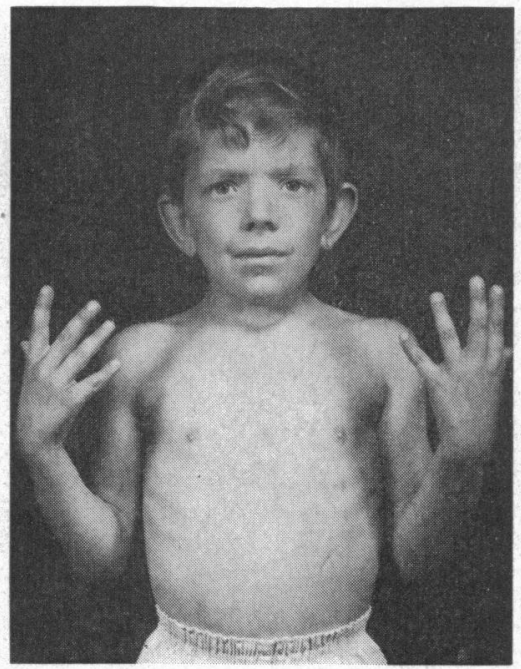

FIG. 4.-Physical appearance of Case 2 at age 7 years.

hypertrophic cardiomyopathy and slight mitral regurgitation (Fig. 8). The attachment of the mitral valve cusps was normal.

Diagnosis. Secundum atrial septal defect with hypertrophic cardiomyopathy, involving the left ventricle.

Case 3. A boy, born by caesarian section for disproportion, birthweight $3288 \mathrm{~g}$. (7 lb. $4 \mathrm{oz}$.), was an only child of normal parents. There was no family history of consanguinity or cardiac abnormality. A heart murmur was heard at 7 months by Dr. Jack Sakula at the Central Middlesex Hospital when the child was admitted during a respiratory infection with severe dyspnoea and apparent heart failure. The electrocardiogram at that time suggested severe left ventricular hypertrophy, with inversion of the $T$ waves in the left ventricular leads, and at 3 years was little altered except for a further increase in voltage (Fig. 9).

The heart failure responded to digitalis and diuretics and slow improvement was made, and he remained well except for effort dyspnoea after the age of 1 year. Physical signs at 3 years (1967) showed a normally grown child with a small slightly jerky arterial pulse and a normal jugular venous pressure and pulse. The cardiac impulse revealed a powerful left ventricular thrust. On auscultation there was an ejection click immediately preceding a long loud systolic ejection murmur at the left sternal edge, which was conducted to the neck. The second heart sound was single (Fig. 10). At the apex there was a late systolic murmur and a third heart sound. Occasionally the apical murmur became pansystolic.

Chest radiographs showed post-stenotic dilatation of the ascending aorta, a full-sized left ventricle, and slight left atrial enlargement.

Cardiac catheterization at $2 \frac{1}{2}$ years (1966), by Dr. Malcolm Towers, showed a $20 \mathrm{~mm} . \mathrm{Hg}$ systolic gradient across the aortic valve under general anaesthesia.

Left ventricular angiocardiography confirmed the presence of slight aortic valvar stenosis and showed evidence of mitral regurgitation, as well as appearances suggestive of hypertrophic cardiomyopathy (Fig. 11). Subsequent right ventricular angiocardiography 3 days before operation in September 1967 confirmed that

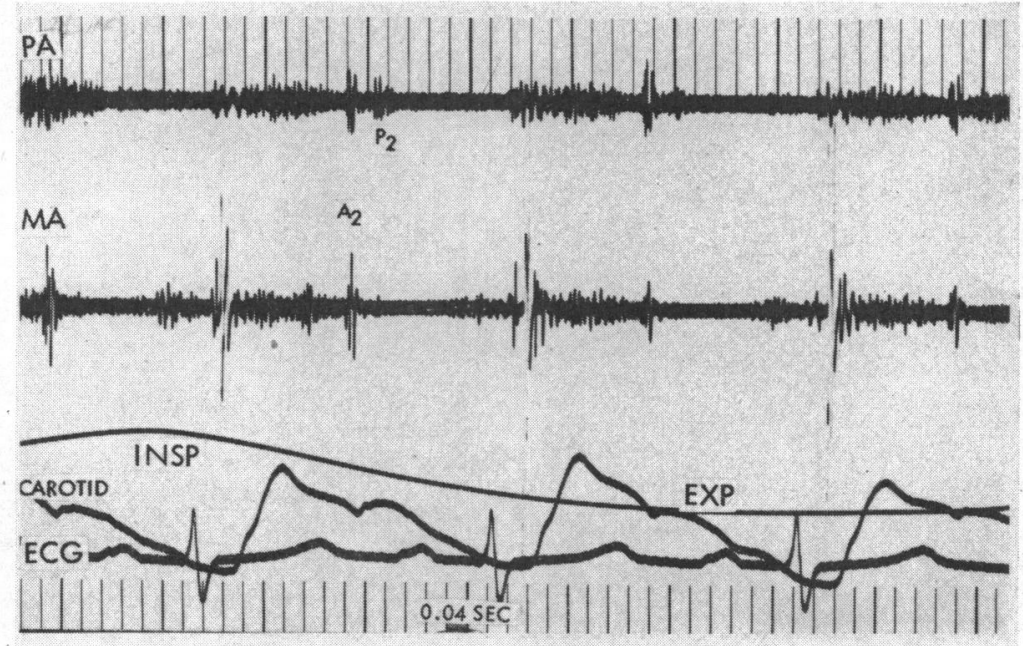

Fig. 5.-External phonocardiogram from Case 2 showing wide splitting of the second heart sound at $0.05-$ $0.06 \mathrm{sec}$. in the pulmonary area (PA) with an ejection systolic murmur. In the mitral area (MA) there is an atrial systolic murmur and a pansystolic murmur. $A_{2}=$ aortic valvar closure; $P_{2}=$ pulmonary valvar closure; INSP = inspiration; EXP = expiration; CAROTID, external carotid arterial tracing, ECG = electrocardiogram. 


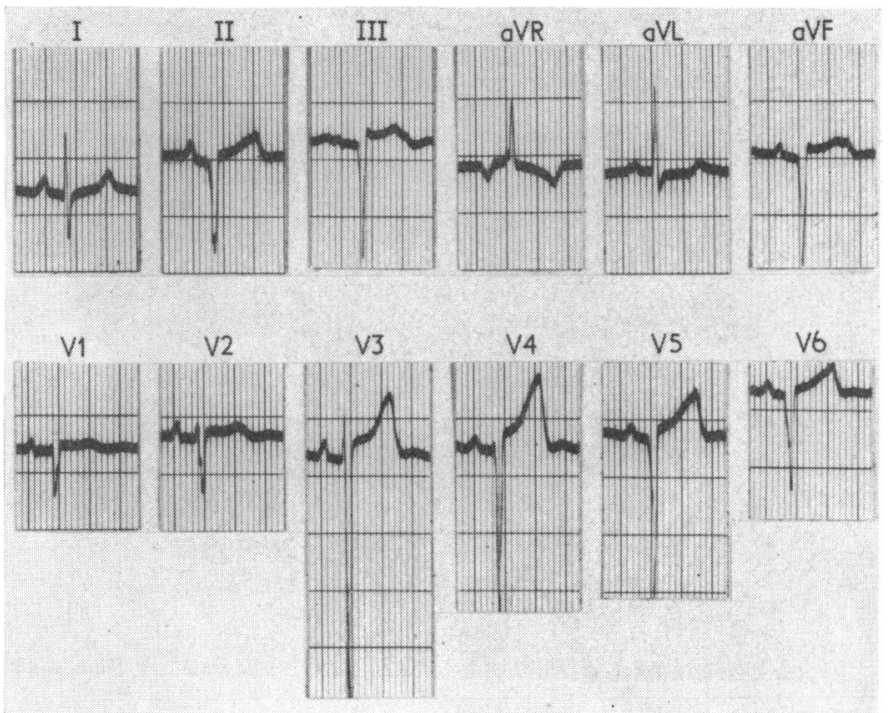

FIG. 6.-Electrocardiogram from Case 2 with an ostium secundum atrial septal defect, showing left axis deviation and QS patterns in leads II, III, VF, V5, and V6.

abnormal muscle was encroaching on the right ventricular outflow tract (Fig. 11c).

Operation was performed by Mr. Donald Ross in September 1967. A mildly stenosed bicuspid aortic valve was partially opened by cutting two fused commissures. Beneath the aortic valve the septum bulged into the outflow tract and gripped the surgeon's finger in systole. A longitudinal cut into the muscle was made down to the level of the insertion of the papillary muscle,

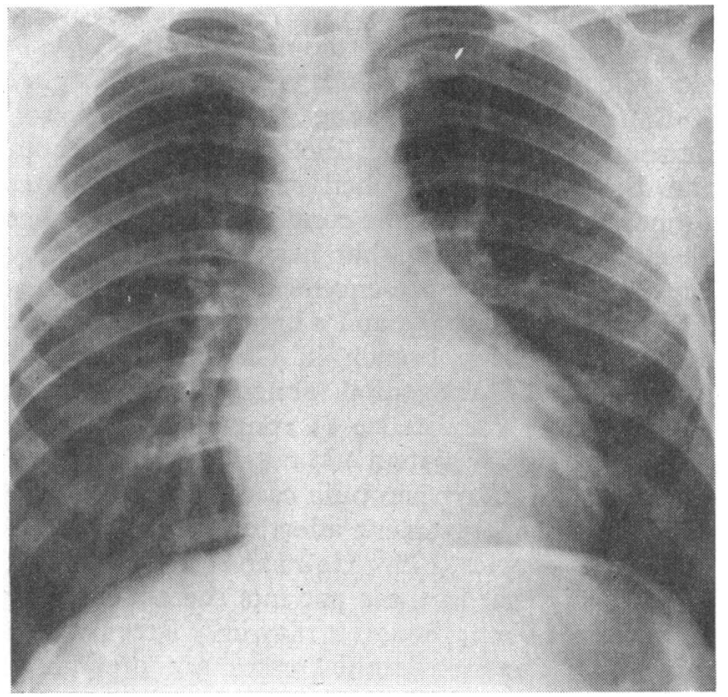

Fig. 7.-Chest $x$-ray film from Case 2 with an atrial septal defect, showing cardiomegaly, some pulmonary plethora, and enlargement of the left atrium. and muscle from the septum was sent to Professor Anthony Pearse for histochemical study. Following operation there was a small gradient across the outflow tract, and the pulse became jerky without evidence of aortic regurgitation.

The child made a good recovery after operation. Transient left bundle-branch block was present in the first post-operative week, and then the pattern of severe left ventricular hypertrophy returned. Six months later the child was without symptoms. The pulse was slightly jerky, the ejection click was loud and late, and the ejection systolic murmur short and soft. A variable pansystolic murmur was still heard at the apex. The electrocardiogram showed upright $T$ waves in the anterior left ventricular leads, but loss of $R$ waves in V2 and V3 (Fig. 9b).

The histochemical report from Professor Anthony Pearse stated that the muscle showed only minimal changes that are usually associated with hypertrophic

TABLE II

FINDINGS AT CATHETERIZATION IN CASE 2

\begin{tabular}{|c|c|c|}
\hline & Pressures (mm.Hg) & $\begin{array}{c}\text { Oxygen saturation } \\
(\%)\end{array}$ \\
\hline $\begin{array}{l}\text { Superior vena cava } \\
\text { Right atrium }\end{array}$ & $\begin{array}{ll}a=8 & v=2 \\
x=0 & y=0\end{array}$ & $\begin{array}{l}66,70 \\
\text { High } 67 \\
\text { Mid } 96 \\
\text { Low } 93\end{array}$ \\
\hline $\begin{array}{l}\text { Right ventricle } \\
\text { Pulmonary artery } \\
\text { Left atrium } \\
\text { Femoral artery } \\
\text { Left ventricle }\end{array}$ & $\mathrm{a}=\begin{array}{l}34 / 0 \\
29 / 8 \\
8 \mathrm{v}=6 \\
90 / 50 \\
90 / 0\end{array}$ & $\begin{array}{l}81,83 \\
84 \\
96 \\
98 \\
98\end{array}$ \\
\hline
\end{tabular}

Cannon waves in the right atrium during nodal tachycardia $=35 \mathrm{~mm} . \mathrm{Hg}$. 


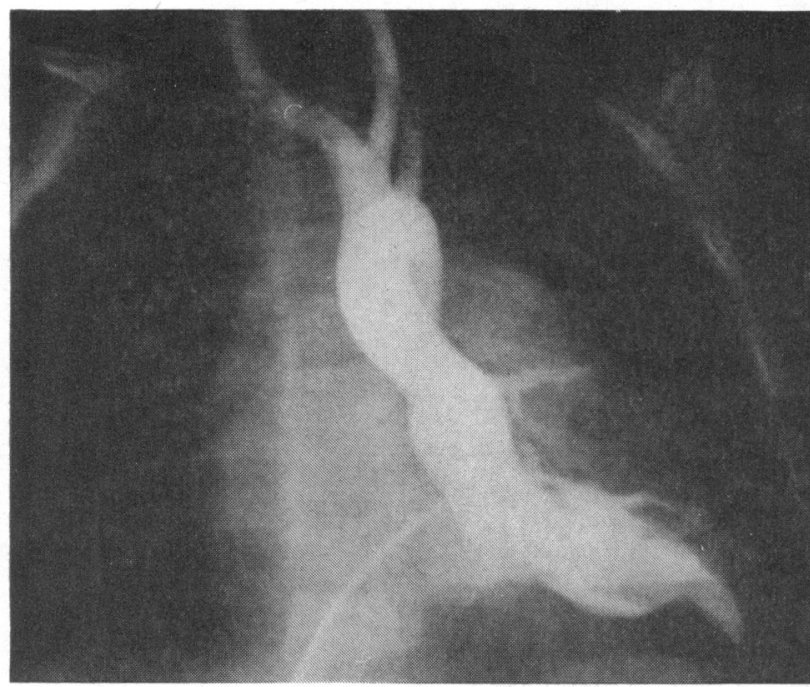

(a)

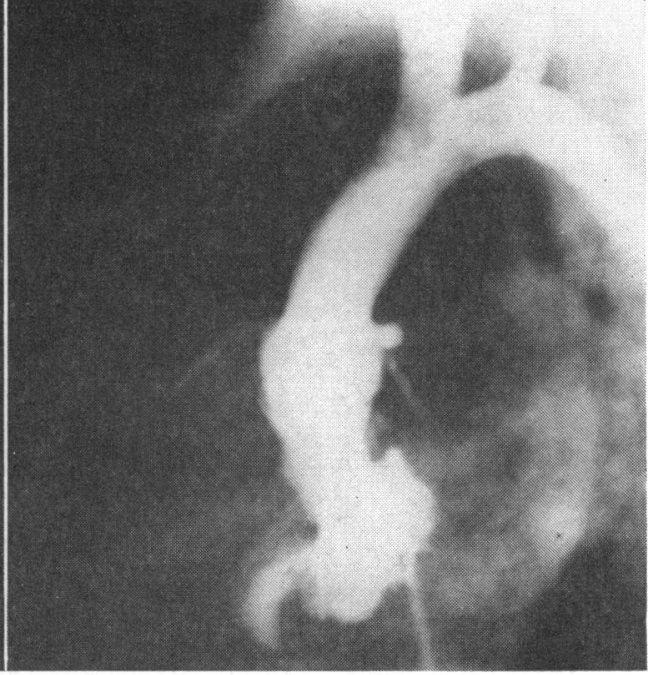

(b)

FIG. 8.-Left ventricular angiocardiograms from Case 2. (a) Antero-posterior view, showing a normal atrioventricular septum on the medial border and normal attachment of the posterior cusp of the mitral valve. Muscle masses are seen to be encroaching on the cavity of the left ventricle and there is hypertrophy of its free wall. The first aortic branch consists of a brachiocephalic trunk. (b) Left lateral view showing slight opacification of the left atrium from mitral regurgitation and gross septal hypertrophy encroaching on the outflow tract.

obstructive myopathy. There was an increased mitochondrion/myofibril ratio, with no increase in lysosomes.

Diagnosis. Aortic valvar stenosis with biventricular hypertrophic cardiomyopathy.

\section{Discussion}

It is difficult to know if the presence of congenital heart disease with hypertrophic cardiomyopathy is a chance association or whether it has significance. Although congenital heart disease occurs in approximately 6 per 1000 live births (Carlgren, 1959), the incidence of hypertrophic cardiomyopathy in the general population is unknown, thus making any prediction about the coexistence of the two conditions impossible.

Hypertrophic cardiomyopathy has, however, been found with various congenital heart lesions, such as atrioventricular defect (Molthan, Paul, and Lev, 1962), ventricular septal defect (Lauer, DuShane, and Edwards, 1960; Walther, Madoff, and Zinner, 1960), coarctation of the aorta (McIntosh et al., 1962), and persistent ductus arteriosus (Goodwin et al., 1960). These reports, and the three further cases that are presented, suggest that the association is more than chance. It is also possible that hypertrophic cardiomyopathy results from an abnormality in utero, which causes the heart muscle to grow abnormally, just as some intrauterine factor, either genetic or environmental, may give rise to congenital abnormalities of the valves or cardiac septa.

The congenital nature of some cases of hypertrophic cardiomyopathy has been shown by Neufeld, Ongley, and Edwards (1960) who described a stillborn baby and a 1-month-old boy with the condition. The early recognition of cardiomyopathy in a 1-yearold child reported by Daoud, Gallaher, and Kaplan (1961) and in other young children (Fishleder, Bermúdez, and Friedland, 1962; Wigle, Chrysohou, and Bigelow, 1963; Cohen et al., 1964) further supports the view that the condition may sometimes be congenital, a view that has been accepted by Lurie (1962). The presence of some of the features of Turner's phenotype, and a brachiocephalic trunk as the first aortic branch in Case 2, shows the multiplicity of congenital abnormalities in this patient. The coexistence of congenital lesions in the cardiovascular system and outside it is common.

Patients with hypertrophic cardiomyopathy may have familial involvement affecting more than one generation (Davies, 1952; Hollman et al., 1960). It seems likely that in these patients the abnormality is present at birth, though it may only later become manifest. The non-familial cases are predominantly male (Braunwald et al., 1964), and it may be relevant that the 3 patients in the present series were male. 

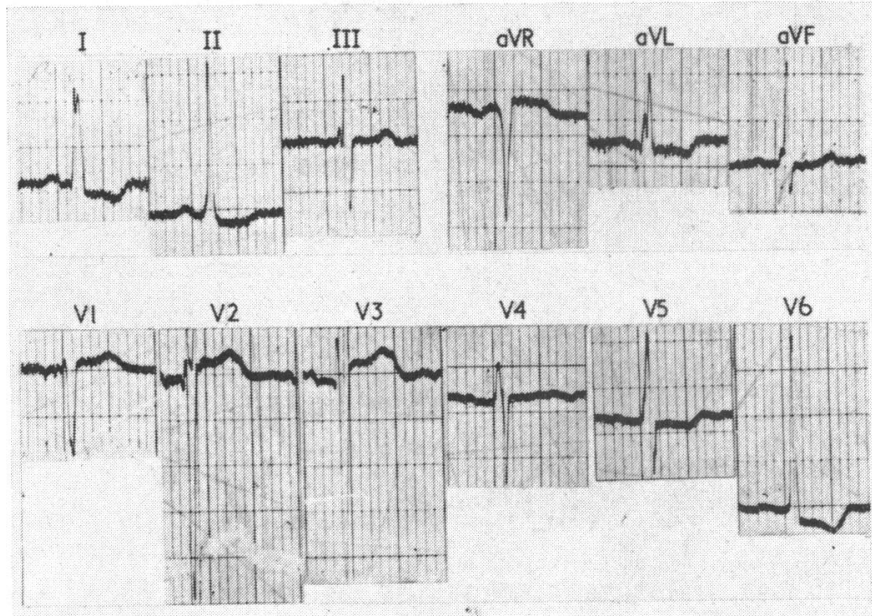

(a)

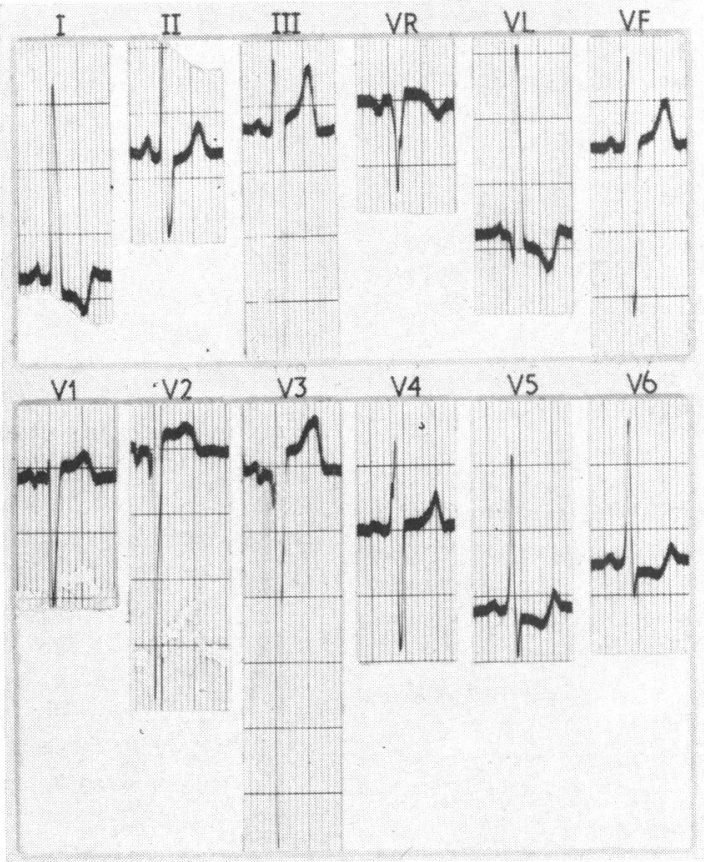

(b)

FIG. 9.-Electrocardiograms from Case 3 with trivial aortic valvar stenosis. (a) Before operation showing changes of left ventricular hypertrophy; (b) 4 months after operation showing $T$ waves over the left ventricle, which have become diphasic.

In the presence of a stenotic semilunar valve, the possibility that the muscular hypertrophy is secondary to the valvar abnormality must be considered. This is, of course, the rule both on the left and the right sides of the heart in patients who have severe valvar stenosis over a period of years, and furthermore they may develop secondary subvalvar obstruction following relief of the pulmonary or aortic valvar stenosis. In the patients with pulmonary (Case 1) and aortic (Case 3) valvar lesions, 


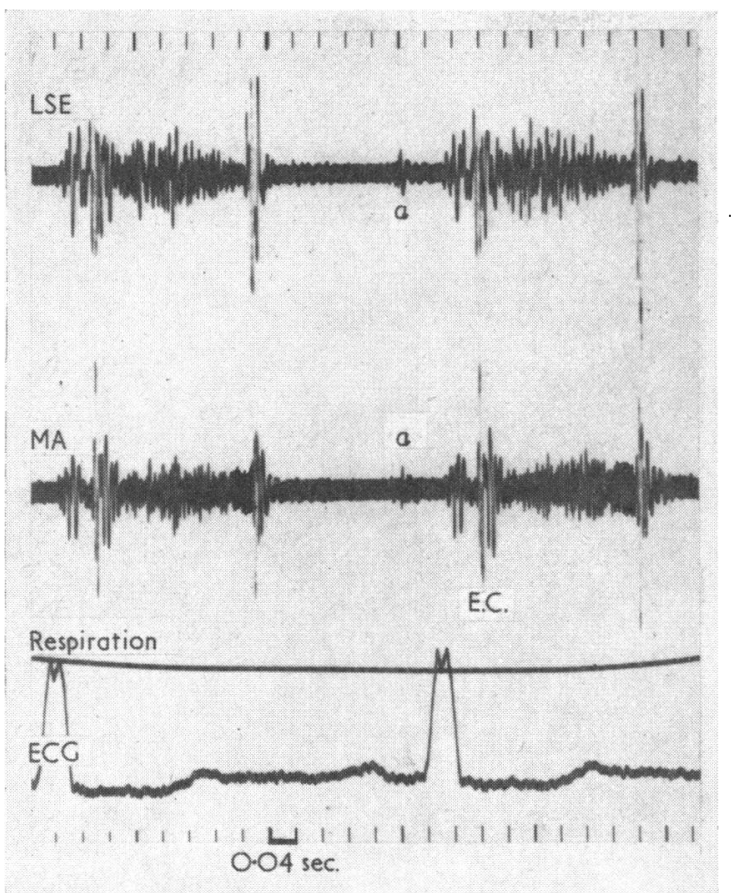

Fig. 10.-External phonocardiogram from Case 3 before operation. At the left sternal edge (LSE) and the mitral area (MA) an ejection click (E.C.) is recorded. The murmur at the left sternal edge (LSE) is of long ejection type, and at the mitral area (MA) is late systolic. An atrial sound is recorded on both channels. The second sound is single. ECG = electrocardiogram.

both of these were mild and therefore would not cause the extreme degree of ventricular hypertrophy that was present. Furthermore, the apparent involvement of both sides of the heart and ventricular septum in the hypertrophic process could not be caused by a stenosis of one semilunar valve, however severe. The left ventricular hypertrophy in Case 2 could not be related to the presence of a secundum type of atrial septal defect, and the associated mitral regurgitation was relatively mild and thus not the cause of the grossly abnormal left ventricular muscle. Therefore, it seems reasonable to conclude that these cases are all examples of two independent diseases of the heart occurring in the same patient.

The physical signs in these patients arose from pulmonary stenosis, an atrial septal defect, and aortic stenosis. The presence of important associated hypertrophic cardiomyopathy was suggested in Case 1, with pulmonary valvar stenosis, by the changes in the serial electrocardiograms. The child with the secundum atrial septal defect was originally referred as a case of ostium primum atrial septal defect. Scrutiny of the electrocardiogram showed that, though there was left axis deviation, the electrocardiogram was atypical for an atrioventricular defect, in that $Q S$ patterns instead of $Q R$ complexes were present in leads II and III and the left chest leads. In the youngest patient (Case 3) with mild aortic valvar stenosis, the diagnosis of associated cardiomyopathy was difficult. The early deterioration with severe electrocardiograpic change during infancy, with comparative well-being for $2 \frac{1}{2}$ years without relief of the offending obstruction, suggested another cause than simple aortic valvar stenosis. In all three patients the diagnosis of hypertrophic cardiomyopathy was made from the appearance of the left ventricular angiocardiograms. All had mitral regurgitation which was most severe in the eldest patient, and mild in the others. In the two patients (Cases 1 and 2) who had right ventricular angiocardiograms, the right side of the heart, particularly the ventricular septum, was affected by the myopathic process.

The combination of hypertrophic cardiomyopathy and a congenital valvar or septal abnormality may pose a difficult therapeutic problem. It may be dangerous to close an atrial septal defect and leave an important left-sided lesion. For this reason operation was not recommended in Case 2, though it is possible that closure of the defect combined with myotomy on the left side might improve the prognosis. In the patient with pulmonary valvar stenosis the lesion was mild and did not require valvotomy. On the other hand, the decision about operation was more difficult in the child with mild aortic valvar stenosis, since this lesion must act as a stimulus to hypertrophy, even when mild. This child appeared to benefit from operation on the aortic valve and myotomy of the left ventricular outflow tract; he lost his effort dyspnoea, and the electrocardiogram improved. These changes may have been due either to the valvotomy, or to the myotomy, or to both.

The recognition of associated hypertrophic cardiomyopathy with congenital valvar and septal lesions of the heart is of extreme importance, as it governs therapy and may prejudice the results of operation. The long-term prognosis must be guarded.

\section{SUMMARY}

Congenital heart disease in association with hypertrophic cardiomyopathy is described in three patients. The cardiac lesions were pulmonary valvar stenosis, atrial septal defect, and aortic valvar stenosis. The significance of these findings in regard to the aetiology of hypertrophic cardiomyopathy is discussed. 


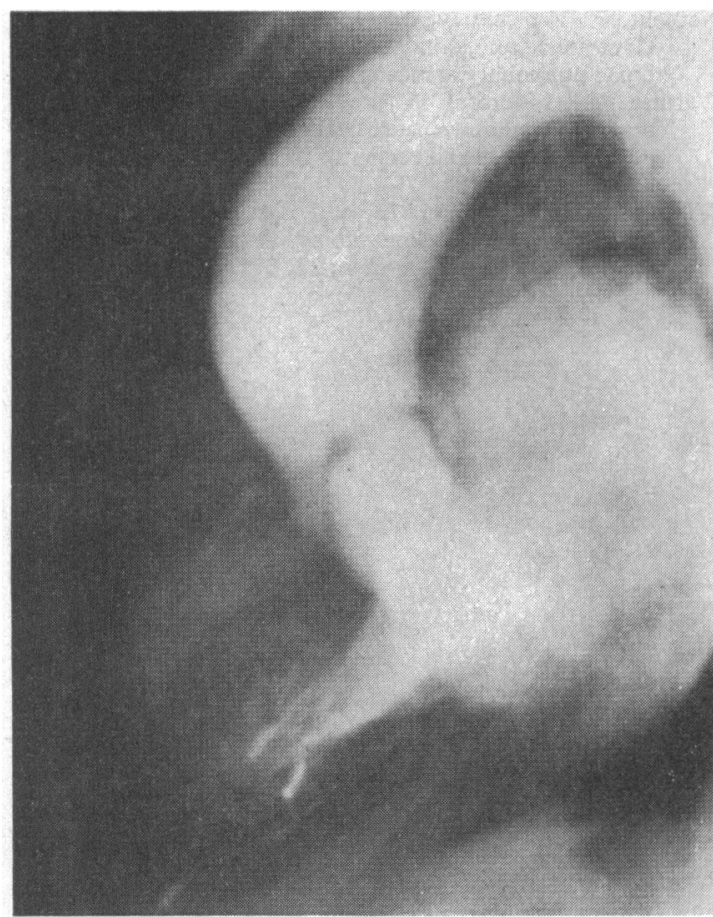

(a)

FIG. 11-(a) and (b) Left ventricular angiocardiogram from Case 3 showing massive hypertrophy of the free wall and septum, left atrial filling from mitral regurgitation, and the domed mildly stenotic aortic valve. (a) Left lateral view; (b) antero-posterior view. (c) Right ventricular angiocardiogram showing narrowing of the cavity of the right ventricular body, and the hypertrophied ventricular septum encroaching on the right ventricular outflow tract.

\section{REFERENCES}

Braunwald, E., Lambrew, C. T., Rockoff, S. D., Ross, J., and Morrow, A. G. (1964). Idiopathic hypertrophic subaortic stenosis. Circulation, 29-30, Suppl. 4, p. IV-1.

Carlgren, L. -E. (1959). The incidence of congenital heart disease in children born in Gothenburg 1941-1950. Brit. Heart f., 21, 40.

Cohen, J., Effat, H., Goodwin, J. F., Oakley, C. M., and Steiner, R. E. (1964). Hypertrophic obstructive cardiomyopathy. Brit. Heart f., 26, 16.

Daoud, G., Gallaher, M. E., and Kaplan, S. (1961). Muscular subaortic stenosis. Amer. F. Cardiol., 7, 860.

Davies, L. G. (1952). A familial heart disease. Brit. Heart F., 14, 206.

Fishleder, B. L., Bermúdez, F., and Friedland, C. (1962). Estenosis subaortica dinamica. Su diagnostico clinico y por metodos graficos externos. Arch. Inst. Cardiol. Méx., 32, 430.

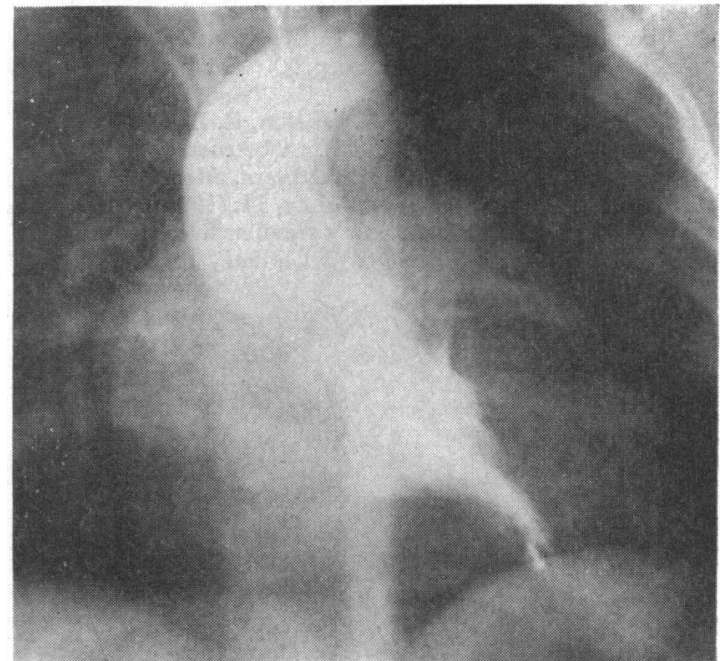

(b)

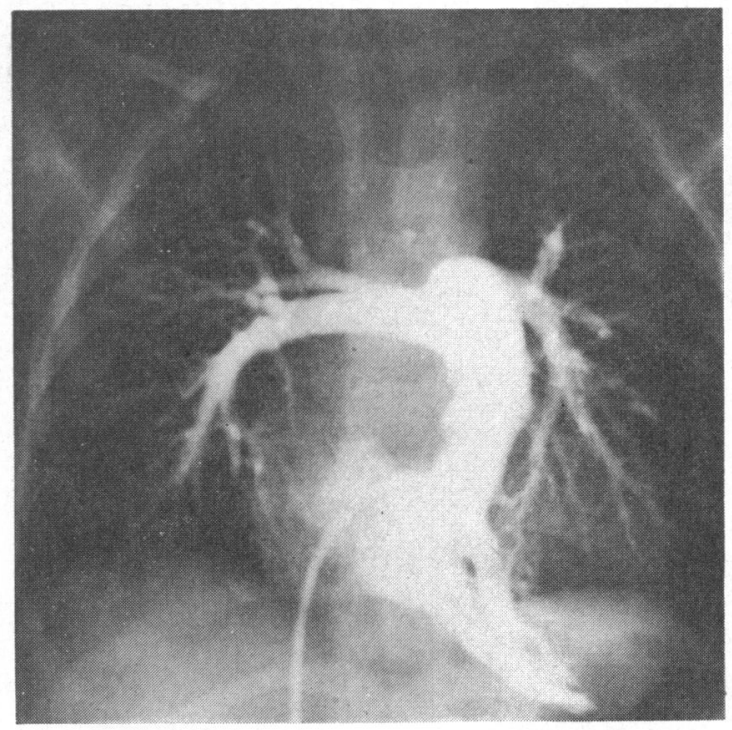

(c)

Goodwin, J. F., Hollman, A., Cleland, W. P., and Teare, D. (1960). Obstructive cardiomyopathy simulating aortic stenosis. Brit. Heart f., 22, 403.

Hollman, A., Goodwin, J. F., Teare, D., and Renwick, J. F. (1960). A family with obstructive cardiomyopathy (asymmetrical hypertrophy). Brit. Heart f., 22, 449.

Lauer, R. M., DuShane, J. W., and Edwards, J. E. (1960). Obstruction of left ventricular outlet in association with ventricular septal defect. Circulation, 22, 110. 
Lurie, P. R. (1962). Obstructive ventricular hypertrophy in congenital heart disease. In Congenital Heart Disease: An International Symposium, p. 90 . Ed. by D. P. Morse. F. A. Davis, Philadelphia.

McIntosh, H. D., Sealy, W. C., Whalen, R. E., Cohen, A. I., and Sumner, R. G. (1962). Obstruction to outflow tract of left ventricle. Arch. intern. Med., 110, 312.

Molthan, M. E., Paul, M. H., and Lev, M. (1962). Common A-V orifice with pulmonary valvular and hypertrophic subaortic stenosis. Amer. F. Cardiol., 10, 291.
Neufeld, H. N., Ongley, P. A., and Edwards, J. E. (1960). Combined congenital subaortic stenosis and infundibular pulmonary stenosis. Brit. Heart f., 22, 686.

Walther, R. J., Madoff, I. M., and Zinner, K. (1960). Cardiomegaly of unknown cause occurring in a family. Report of three siblings and review of the literature. New Engl. f. Med., 263, 1104.

Wigle, E. D., Chrysohou, A., and Bigelow, W. G. (1963). Results of ventriculomyotomy in muscular subaortic stenosis. Amer. F. Cardiol., 11, 572. 